\section{Journal of Vascular Research}

\title{
Vascular Update: A New Review Series
}

A current search of the term 'vascular' for the year 2008 reveals 27,291 hits in PubMed and this number represents only a snapshot in time as new publications are continuously added to this field. This number rates even higher than numbers found for terms like hypertension, diabetes and neurodegenerative diseases, each of note, being diseases related to the vascular system. Since no one is able to cope with such a flood of publications it becomes more and more important to get structured information from experts who survey their respective fields and provide this information usually in the form of focused reviews. Other than Original Articles, which are usually smaller in scope and reflect ongoing research in specialised sectors of the field, Reviews assemble findings into a more general framework and provide unique perspectives that can put singular results, which sometimes happen to be as spectacular as they are short-lived, into a more critical context. The review of the literature by experts is therefore absolutely indispensable for the further development of the field and for refining our understanding. Reviews are especially important for generating and advancing new concepts. In the field of basic vascular research, in which the Journal of Vascular Research is specialised, we have a significant interest in vascular signaling. The development in the field of vascular signaling has been and continues to be particularly fast paced and exciting. It is therefore logical for the Journal of Vascular Research to initiate the development of a new series of comprehensive reviews aimed at this and other evolving fields in vascular biology. The primary goal of these reviews will be to provide new perspectives and updates on the exploding body of knowledge emerging in rapidly expanding fields of vascular biology. In addition to summarising knowledge, the reviews will serve as emissaries for novel concepts regarding their significance for vascular diseases and/or how they may challenge the validity of existing paradigms. We decided to call this review series 'Vascular Update'. We hope that the views of experts in the field will generate added value to our readers, stimulate further scientific discussions and encourage scientists to submit related work to the Journal of Vascular Research. In this context, we remind especially the young scientists that their articles compete for the Journal of Vascular Research Award given every two years by the publishers in conjunction with the European Society of Microcirculation for the article that has been rated highest by an international jury of their peers.

Ulrich Pohl, Munich

Gerald Meininger, Columbia, Mo.

\section{KARGER}

Fax +41 613061234 E-Mail karger@karger.ch www.karger.com
(C) 2009 S. Karger AG, Base

1018-1172/09/0465-0503\$26.00/0 